\title{
PEDAGOGIAS DECOLONIAIS NO CONTEXTO DE PANDEMIA DO COVID- 19 | DESAFIOS E POSSIBILIDADES DO FAZER DOCENTE
}

Decolonial pedagogies in the context of covid-19 pandemic: challenges and possibilities of

teaching practice

LOUREIRO, Camila Wolpato ${ }^{1}$.

Resumo: 0 esforço de refletir sobre o nosso próprio tempo é tão difícil quanto fundamental. Através de tal desafio, a pesquisa apresentada aqui é uma proposta para pensarmos sobre o papel profissional do professor/a no Brasil, em uma conjuntura de crise provocada pela pandemia do COVID-19, juntamente com a crise do capitalismo mundial. Para tanto, partimos da metodologia da pesquisa bibliográfica, investigando a literatura que vem debatendo sobre as principais implicações políticas, sociais e econômicas do atual momento histórico. Mais do que isso, olhamos para a construção de um campo pedagógico a partir da chave dos estudos decoloniais. Tais pressupostos nos fornecem base para olharmos para os problemas por meio da dialética freiriana de denúncia/anúncio, fazendo dois movimentos centrais: a) denunciar os desafios do fazer docente crítico no atual contexto; b) anunciar alternativas de superação, que vem sendo construídas pelos movimentos sociais populares e que podem ser lidas na chave de estudos decoloniais.

Palavras-chave: Pedagogias Decoloniais. Pandemia COVID-19. Educação Popular. Movimentos Sociais.

Abstract: The effort of reflecting about our own time is as difficult as it is fundamental. Through this challenge, this research is a proposal for us to think about the teacher's role in Brazil as a professional in a time of crisis caused by the Covid-19 pandemic, along with the world capitalism system crisis. Thus, we started with a bibliographical research, inquiring the literature about the main political, social and economical implications of the current historical moment. More than that, we look at the construction of a pedagogical field, having the Decolonial Studies as a theoretical key. These assumptions allow us to support our perception about the problem on the Freire's dialectic of denonciation/announcement, by two main movements: a) denounce the challenges of the critical teaching practices in the current context; b) announce the overcoming alternatives that are being built by popular social movements, and which can be understood by the key of decolonial studies.

Keywords: Decolonial Pedagogies. COVID-19 Pandemic. Popular Education. Social Movements.

\footnotetext{
${ }^{1}$ Doutoranda no Programa de Pós-Graduação em Educação, pela Universidade do Vale do Rio dos Sinos, na linha de pesquisa Educação, Desenvolvimento e Tecnologias. Mestra (bolsista CAPES/ FAPERGS) pelo Programa de Pós-Graduação Interdisciplinar em Ciências Humanas, pela Universidade Federal da Fronteira Sul/ Campus Erechim. https://unisinos.academia.edu/CamilaWolpatoLoureiro
} 
${ }^{1}$ Doutoranda no Programa de Pós-Graduação em Educação, pela Universidade do Vale do Rio dos Sinos, na linha de pesquisa Educação, Desenvolvimento e Tecnologias. Mestra (bolsista CAPES/ FAPERGS) pelo Programa de Pós-Graduação Interdisciplinar em Ciências Humanas, pela Universidade Federal da Fronteira Sul/ Campus Erechim.

1 Ainda são esparsas as publicações sobre a temática, não havendo nenhuma determinação de qual designação sobre o vírus é mais adequada para ser usada no Brasil. Assim, opto por utilizar a sigla internacional de Corona Vírus Desease-2019 (COVID-19).

${ }^{1}$ A atual crise do capitalismo, iniciada em 2007 nos Estados Unidos da América, por meio de uma bolha de especulação financeira, se deu a partir da expansão de crédito e da renda fictícia. "Na América Latina, a desaceleração, queda de preços, forte redução da produção industrial e das exportações, desemprego, etc. se manifestaram desde agosto-setembro de 2008." (CANO, 2009, p. 610). Vale ressaltar que a atual crise tem sido mais intensa e extensa que as anteriores, uma vez que experimentamos um período de globalização mercantil e financeira - juntamente com a desregulação financeira -, que estimularam uma enorme volatilidade e especulação internacional de bens e valores. Para saber mais, ver: "América Latina: notas sobre a crise atual", de CANO, 2009.

${ }^{1}$ A expressão "Abya Yala" - que significa, na língua do povo Kuna, "terra em sua plena maturidade" - vem sendo cada vez mais usada e propõe a construção de um sentimento de unidade e pertencimento entre os povos submetidos à colonização. Tenho ciência que o termo é historicamente dinâmico e polissêmico e que é interpretado de diversas formas por grupos sociais e políticos (acadêmicos ou não) ao longo do subcontinente. Entretanto, sem menosprezar as relações de dominação e resistência em toda a América Latina, a partir de um arcabouço teórico mobilizado pelos estudos decoloniais e algumas discussões não-coloniais, compreendo que o uso do termo Abya Yala denota uma epistemologia que pensa a América Latina a partir de si e para si.

${ }^{1}$ Vale ressaltar que a investigação aqui apresentada é parte de pesquisa de doutorado em andamento, com recorte específico para o contexto político, social, econômico em que estamos inseridos/as.

${ }^{1} \mathrm{Na}$ complexidade da realidade social e política brasileira, não podemos esquecer, também, da crescente intervenção do Superior Tribunal Federal, a partir de ações e decisões positivas e determinantes, derrubando medidas dos governos federal, estaduais e municipais. Além das amplas e diversas manifestações de grupos insatisfeitos com o confinamento físico imposto por estados e municípios.

${ }^{1}$ Através de diálogo com Paulo Freire, em "Pedagogia da esperança: um reencontro com a pedagogia do oprimido" (1992), Márcio D’Olne Campos utiliza a expressão "sulear". De acordo com D’Olne Campos, o “Sul” é um referente ou ponto de vista que se opõe aos determinismos, a dicotomização e preconceitos. Indica a relevância pela busca da descolonização da ciência.

${ }^{1}$ É importante afirmarmos que as pedagogias decoloniais não sinônimas das pedagogias latino-americanas. Essas últimas dizem respeito à todas as formas de produção intelectual pedagógica construídas em Abya Yala, mas que não necessariamente questionem os paradigmas europeus e norte-americanocentrados. Para saber mais sobre a temática, sugiro a leitura dos livros: a) "Fontes da Pedagogia Latino-Americana: uma antologia", organizado por STRECK, 2010; b) E também "Fontes da Pedagogia Latino-Americana: heranças (des)coloniais", organizado por STRECK; MORETTI; ADAMS, 2019.

${ }^{1}$ Vale destacarmos que apenas o uso de mídias digitais em si mesmas, não necessariamente está dentro do campo de produção da educação à distância. E é nesse sentido que estamos entendendo o trabalho atual de professores/as-educandos/as que estão, antes se adaptando ao contexto não presencial, do que refletindo sobre as suas práticas e teorias.

10 resumo técnico se encontra disponível em: <https://www.docencia.net.br/news>. Acesso em $28 / 07 / 2020$. 
A pandemia do COVID-19 expõe uma crise global, sanitária, política, econômica e social como em poucos momentos históricos vimos antes. ${ }^{2}$ Pierre Dardot e Christian Laval (2020) argumentam que esse contexto histórico da pandemia, se configura como um teste para a capacidade das organizações políticas e econômicas lidarem de forma interdependente com o fenômeno. Funcionaria como uma "previa" do que enfrentaremos, enquanto humanidade, em um futuro não tão distante, se as mudanças climáticas seguirem o curso atual. ${ }^{3}$

Atrelado a isso ao fortalecimento de grupos ultraconservadores e de extrema direita, mostram-se importantes desafios para a construção de um espaço pedagógico crítico, libertador, dialógico e decolonial. Como afirma Boaventura de Sousa Santos (2020) a atual pandemia não é uma situação de crise que se contrapõe à uma pretensa situação de "normalidade", mas elemento da crise permanente do capitalismo mundial, que procura legitimar a concentração de riqueza e limar medidas eficazes para impedir a iminente catástrofe ecológica.

Nesse sentido, é fundamental entendermos quais as implicações pedagógicas das crises da pandemia de COVID-19 e do capitalismo mundial. Em que medida é possível o desenvolvimento de um espaço favorável às pedagogias decoloniais, alicerçadas nos conhecimentos da/na Abya Yala? ${ }^{4}$ Não tenho a pretensão de finalizar debates tão amplos em um pequeno espaço de texto. Entretanto, o objetivo desse texto é dar indícios de

\footnotetext{
2 Ainda são esparsas as publicações sobre a temática, não havendo nenhuma determinação de qual designação sobre o vírus é mais adequada para ser usada no Brasil. Assim, opto por utilizar a sigla internacional de Corona Vírus Desease-2019 (COVID-19).
}
${ }^{3}$ A atual crise do capitalismo, iniciada em 2007 nos Estados Unidos da América, por meio de uma bolha de especulação financeira, se deu a partir da expansão de crédito e da renda fictícia. "Na América Latina, a desaceleração, queda de preços, forte redução da produção industrial e das exportações, desemprego, etc. se manifestaram desde agosto-setembro de 2008." (CANO, 2009, p. 610). Vale ressaltar que a atual crise tem sido mais intensa e extensa que as anteriores, uma vez que experimentamos um período de globalização mercantil e financeira - juntamente com a desregulação financeira -, que estimularam uma enorme volatilidade e especulação internacional de bens e valores. Para saber mais, ver: "América Latina: notas sobre a crise atual", de CANO, 2009.
${ }^{4}$ A expressão "Abya Yala" - que significa, na língua do povo Kuna, "terra em sua plena maturidade" - vem sendo cada vez mais usada e propõe a construção de um sentimento de unidade e pertencimento entre os povos submetidos à colonização. Tenho ciência que o termo é historicamente dinâmico e polissêmico e que é interpretado de diversas formas por grupos sociais e políticos (acadêmicos ou não) ao longo do sub- continente. Entretanto, sem menosprezar as relações de dominação e resistência em toda a América Latina, a partir de um arcabouço teórico mobilizado pelos estudos decoloniais e algumas discussões não-coloniais, compreendo que o uso do termo Abya Yala denota uma epistemologia que pensa a América Latina a partir de si e para si.


caminhos de análise a partir de nossa América (MARTÍ, 2007). Para isso, utilizo o método da pesquisa bibliográfica ao me valer de referenciais teóricos para a investigação dos problemas centrais. ${ }^{5}$

Portanto, em uma proposta dialética freiriana, me proponho a denunciar o que esse novo cenário nos traz de desafios para a produção de pedagogias críticas e decoloniais no Brasil, ao mesmo tempo em que procuro anunciar superações possíveis, através da solidariedade própria dos movimentos sociais populares da Abya Yala. Assim, o presente texto mobiliza três eixos centrais: Em um primeiro momento olhamos mais detidamente para o contexto produzido pela pandemia de COVID-19 e suas implicações econômicas e políticas nas vidas das pessoas; Logo em seguida, fazemos uma breve análise da história dos movimentos sociais populares e suas inferências no campo pedagógico, em especial de viés decolonial; Por fim, investigamos as consequências da atual conjuntura de dupla crise (pandemia e capitalismo), para a construção de um espaço de produção de pedagogias decolonias, denunciando os desafios enfrentados por profissionais da educação e anunciando deslocamentos possíveis próprios desse contexto.

\section{PARA ALÉM DE UMA CRISE SANITÁRIA, UMA CRISE SOCIAL E HISTÓRICA}

Muitos/as autores/as e intelectuais vem dialogando sobre o atual momento social, político e histórico produzido a partir da pandemia do COVID-19. Entretanto, a atual pandemia não é a primeira (ou a última) que iremos conhecer na história da humanidade. Talvez o paralelo mais provável, seja com a chamada "gripe espanhola", em 1918 denominação que carrega uma boa dose de xenofobia -, a qual se expandiu de forma acelerada e sem precedentes ao redor do mundo. Segundo Yuval Harari (2020), a gripe matou dezenas de milhões de pessoas, sendo mais brutal do que todas as perdas da Primeira Guerra Mundial.

\footnotetext{
${ }^{5}$ Vale ressaltar que a investigação aqui apresentada é parte de pesquisa de doutorado em andamento, com recorte específico para o contexto político, social, econômico em que estamos inseridos/as.
} 
Certamente a combinação de epidemias com a aceleração dos transportes e o crescimento populacional mundial, tornam-se muito mais potentes, mortais e de difícil contingenciamento. Porém, essa combinação por si só não explica o quadro pandêmico que enfrentamos, e não concordo com quem advoga que a única explicação para a enorme expansão do vírus tenha se dado por conta da globalização. Nessa perspectiva sobre a crise, a alternativa de saída se daria por meio do fechamento de fronteiras, construção de muros, restrição de viagens e de comércios. Pelo contrário, a história das epidemias nos ensina que o "remédio" se dá na cooperação e na solidariedade interpessoal, institucional e social. Como afirma Harari: "A coisa mais importante que as pessoas precisam compreender sobre a natureza das epidemias talvez seja que sua propagação em qualquer país põe em risco toda a espécie humana" (HARARI, 2020, p. 07).

A iminência de uma epidemia em escala global não é algo novo, tendo em vista experiências anteriores como a SARS na China e o Ebola na África Ocidental. A não-ação preventiva encontra respaldo no corporativismo da grande indústria farmacêutica que tem pouco (ou nenhum) interesse em investir em prevenção de crises de saúde pública. Como afirma David Harvey (2020. p. 04): “A prevenção não contribui para o valor do acionista. 0 modelo de negócios aplicado à provisão de saúde pública eliminou as capacidades excedentes de enfrentamento que seriam necessárias em uma emergência". Não estou argumentando que a indústria farmacêutica é responsável pela expansão da transmissão do vírus, mas que a falta de prevenção ajuda a explicar o porquê de hoje vivenciarmos uma verdadeira corrida mundial por uma vacina adequada ao COVID-19.

De qualquer maneira, não podemos aceitar que a condição atual é resultado de uma contingência natural e biológica. Trata-se de uma crise fundamentalmente, social e histórica. Para Alysson Mascaro (2020) os próprios sistemas capitalistas são a crise, uma vez que produzem cenários em que alguns/as possuem os meios de produção e outros/as somente as suas forças de trabalho. Os impactos sociais ficam ainda mais evidentes, quando observamos as dimensões de gênero, raça e classe. Existem aqueles/as que podem trabalhar de forma remota de suas casas (local em que a maioria dos/as professores/as se encontram) e os/as trabalhadores/as dos setores essenciais, que fornecem o básico para as condições de vida social (HARVEY, 2020).

No Brasil, a pandemia é ampliada a partir do desemprego, dos transportes coletivos lotados, da fragilidade do sistema único de saúde, das habitações precárias e 
com espaços insuficientes para quarentenas, entre outros motivos. No campo político, o regressismo e reacionarismo do governo de Jair Bolsonaro assume ares ditatoriais, sem políticas de mitigação do quadro pandêmico. ${ }^{6}$

Para Mascaro (2020) esse movimento de ascensão de líderes de extrema direita o qual junto de Bolsonaro podemos adicionar nomes como Donald Trump, Viktor Orbán, Benjamin Netanyahu, Narendra Modi, entre outros - pode ser chamado de crise como combate à crise. Nessa perspectiva, ao menos três passos são necessários: 1- Negar a potência destrutiva do vírus; 2- Opor-se a própria realidade concreta sobre a qual governam, diminuindo as consequências políticas e sua responsabilidade frente ao número crescente de mortos; 3- Ajudar financeiramente e dando suporte a grandes empresas e bancos, sem propor políticas fortes de diminuição das desigualdades sociais provocadas pela pandemia.

Slavoj Zizek (2020) interpreta que quando Bolsonaro nega a chegada do COVID19, ele se vê confrontado com um inimigo real, e não construído imaginariamente por seus apoiadores/as. Um inimigo capaz de, no limite, diminuir diferenças políticas em prol de um bem comum: a solidariedade da vida. Afirma ainda, que estamos enredados em uma crise que em sua essência é tripla: médica, econômica e de saúde mental.

A análise de Zizek é precisa, mas talvez possamos argumentar que a crise provocada pela pandemia do COVID-19 também evidencia a necessidade de pensar um campo político-intelectual-pedagógico crítico e decolonial. Fundamentalmente como um esforço para compreender o momento histórico em que estamos inseridos/as, além de, uma busca por superação do paradigma capitalista moderno, que desumaniza e submete pessoas e conhecimentos outros.

No mesmo caminho Fidel Tubino (2005) demonstra como a lógica da globalização do modelo neoliberal é (re)produzida a partir da concentração de capital e da produção de desigualdades. E é por isso que não possui capacidade (ou procura) para resolver problemas sociais, pois não questiona a própria lógica da estrutura social moderna.

\footnotetext{
${ }^{6} \mathrm{Na}$ complexidade da realidade social e política brasileira, não podemos esquecer, também, da crescente intervenção do Superior Tribunal Federal, a partir de ações e decisões positivas e determinantes, derrubando medidas dos governos federal, estaduais e municipais. Além das amplas e diversas manifestações de grupos insatisfeitos com o confinamento físico imposto por estados e municípios.
} 
Assim, para Zizek (2020) a alternativa de superação dos "dois vírus" viria pela quebra do capitalismo mundial e pela ascensão de novas formas de comunismos ao redor do globo. Através de um novo "vírus" agora ideológico, para além do Estado-nação, pautado na solidariedade global e na cooperação. Isolacionismo, a construção de novos muros e mais quarentenas não nos levarão a solução do problema. Somente com uma solidariedade ampla e resposta coordenada globalmente, poderemos pensar em mecanismos de superação do quadro que nos acomete, na perspectiva do autor isso se daria por novas formas de comunismos.

Apesar do autor estar falando em uma perspectiva mundial, se apurarmos nosso olhar para a Abya Yala poderemos perceber que talvez esse movimento já venha sendo feito - mesmo que não tenha sido teorizado de tal maneira. Como nos aponta Jean Tible (2013) ainda que o marxismo tenha se pretendido enquanto paradigma universal, se pensarmos Marx (e o marxismo) a partir das lutas sociais, o universal passa a ser o comum, ou seja, a conexão entre múltiplas lutas: "Pensa-se, assim, que para utilizar a potência de Marx hoje, deve-se conectá-lo com uma série de lutas, 'concretas' e 'conceituais'” (TIBLE, 2013, p. 13).

No prefácio da obra de Tible, Michel Löwy nos convida a entender a concretude dessas lutas:

As comunidades indígenas no Brasil e na América Latina se encontram na
primeira linha da luta em defesa da Natureza. Não só por suas mobilizações
locais para proteger os rios e as florestas, contra os projetos faraônicos dos
Estados (Belo Monte!) e contra a intervenção ecocida das multinacionais
petroleiras e mineiras, mas também por sua proposta de um modo de vida
alternativo ao capitalismo neoliberal globalizado: o Sumak Kawsay (Viver Bem).
Estas lutas são antes de tudo indígenas, mas elas se desenvolvem
frequentemente em aliança com os camponeses sem terra, os ecologistas, os
socialistas, as comunidades de base cristãs, com o apoio de sindicatos, partidos
de esquerda, pastorais da terra e pastorais indígenas da Igreja (LÖWY, 2013, p.
12).

Na mesma perspectiva em livro dialogado com Angela Davis, Naomi Klein (2020) argumenta que os próprios sistemas capitalistas criaram as condições para o aprofundamento da atual crise, considerando trabalhadores/as de todo o mundo de forma descartável. Propositivamente Davis (2020) argumenta ser necessário pensarmos em uma infraestrutura global de saúde pública, que só será possível com a luta dos movimentos populares. A autora se detém na questão do encarceramento em massa: “Portanto, o capitalismo global é de fato responsável pela incapacidade de lidar com esta 
pandemia e também é responsável pelo grande número de pessoas presas em centros de detenção e pelo alto preço dos cuidados de saúde, moradia e educação (DAVIS, KLEIN, 2020, p. 16).

Como argumentamos anteriormente, essa é uma crise não somente sanitária, mas também política, intelectual, social e histórica, atravessadas pelas dimensões de gênero, raça e classe. Para Davis (2020) o combate do racismo estrutural irá perpassar pela capacidade de organizações feministas e do aprimoramento da noção de solidariedade internacional: "Mulheres de todas as origens raciais e étnicas, mulheres pobres, mulheres trans - especialmente nos países do sul do mundo" (DAVIS, KLEIN, 2020, p. 17). A perspectiva da autora retira a centralidade europeia e norte-americana da solução dos desafios ocasionados pelas crises da pandemia e do capitalismo mundial, dando destaque para os conhecimentos produzidos no e a partir do Sul global. ${ }^{7}$

Mais do que isso, nos desafia a pensar criticamente sobre o chamado "novo normal", o qual prevê a manutenção de uma racionalidade moderna em que alguns grupos são desumanizados e impedidos de sua vocação ontológica de "Ser Mais" (FREIRE, 1987). Como afirmava Paulo Freire, nas relações opressivas, violência, dominação e opressão, andam lado a lado no processo de desumanização tanto do dominador/, quanto do dominado/a, o primeiro por excesso de poder e o segundo pela falta dele.

Por fim, no livro "O Amanhã não está à venda" o líder e escritor indígena Ailton Krenak (2020, p. 09), sintetiza bem o debate que estamos propondo nesse texto: “Tomara que não voltemos à normalidade, pois, se voltarmos, é porque não valeu nada a morte de milhares de pessoas no mundo inteiro".

\section{AS PEDAGOGIAS DECOLONIAIS ATRELADAS AOS MOVIMENTOS SOCIAIS POPULARES}

O debate do giro decolonial tem crescido significativamente na Abya Yala, principalmente nos países andinos. No Brasil o debate é mais recente, mas não menos

\footnotetext{
7 Através de diálogo com Paulo Freire, em "Pedagogia da esperança: um reencontro com a pedagogia do oprimido" (1992), Márcio D’Olne Campos utiliza a expressão “sulear”. De acordo com D’Olne Campos, o "Sul” é um referente ou ponto de vista que se opõe aos determinismos, a dicotomização e preconceitos. Indica a relevância pela busca da descolonização da ciência.
} 
potente, dialogando com diferentes campos do conhecimento como Ciências Sociais, Estudos Culturais, Filosofia, História e Educação (LOUREIRO; et al., 2020, p. 57). De forma breve, podemos entender a decolonialidade como um esforço para perceber as implicações da colonização e da colonialidade na construção social, política, intelectual da Abya Yala. Atuando, ao mesmo tempo, para valorizar propostas de ser e estar a partir de conhecimentos próprios desse lugar que é mais do que geográfico, sendo também político e epistemológico. Então, a opção político-intelectual da decolonialidade não prevê um retorno à um passado pré-colonial, mas é uma busca por transgredir a negação ontológica, epistêmica e cosmogônica-espiritual que age para a desumanização/ racialização/ opressão de homens e mulheres do Sul global.

Vale ressaltar que o termo "(de)colonialidade" não foi inventado no âmbito intelectual do século XXI. Como afirma Catherine Walsh (2014), por mais de 500 anos os povos indígenas e afro-caribenhos vem empreendendo lutas decoloniais. E por isso, precisamos estar atentos/as a alguns riscos envolvidos no crescimento do debate se tornar exclusivamente acadêmico, deixando de lado a sua dimensão política de lutas de (re)existência das populações afrodiaspóricas, africanas, indígenas e terceiro-mundistas (BERNARDINO-COSTA; MALDONADO-TORRES e GROSFOGUEL, 2018). Quando dialogamos sobre a produção de pedagogias dentro da chave decolonial, na conjuntura das duas crises (pandemia do COVID-19 e do capitalismo mundial), necessariamente devemos perceber a historicidade política e de lutas sociais do sub-continente.

No século XX a Abya Yala estava imersa em uma atmosfera política, econômica, social e intelectual marcada por conflitos e rebeldias. No ambiente político, surgiram figuras importantes ligadas a grupos socialistas e progressistas, como Ernesto "Che" Guevara e Fidel Castro. Com a adesão de membros das classes médias, o ressurgimento da guerrilha e das lutas armadas deslocaram as lutas do campo para os centros urbanos, culminando em experiências conhecidas como, por exemplo: as guerrilhas da "Frente Amplio" (no Uruguai) ou a "Monteneros-Peronistas" (na Argentina). Além dos famosos casos: da Revolução Mexicana (1910-1917); da insurreição em El Savador (1932); da Revolução Cubana (1953-1959); da Revolução Boliviana (1952); da Revolução Nicaraguense (1970); entre outras (TORRES, 1996).

Atualmente o continente continua sendo palco de lutas e questionamentos às colonialidades, como por exemplo as enormes manifestações no início da segunda década 
dos anos 2000. Ainda que difusos, os processos insurgentes no Chile (2011 e 2012), no México (2012), no Peru (2013) e no Brasil (2013), são reflexos da falta de representações políticas (inclusive dentro dos movimentos sociais) e da consolidação da agenda neoliberal (STRECK, MORETTI, PITANO, 2018).

Podemos afirmar, então, que as lutas sociais também são cenários pedagógicos de (re) (des) aprendizagem: "anunciam a desconformidade, com a oposição a condição de dominação e opressão, organizando-se para intervir; o propósito: derrubar a situação atual e fazer possível outra coisa" (WALSH, 2013, p. 29). 0 movimento indígena zapatista (no México) com seu Sistema Educativo Rebelde e Autônomo Zapatista - juntamente com outros movimentos negros, indígenas, de mulheres, camponeses, organizados pelo continente - são exemplos de lutas concretas por paradigmas outros que questionam o sentido do poder político na região (STRECK, MORETTI, 2013).

É nesse tempo histórico que podemos perceber a contribuição do educador pernambucano Paulo Freire, o qual desenvolveu ampla literatura na busca de pensar alternativas intencionalmente contra-hegemônicas. A partir do estudo de João Colares da Mota Neto (2016) e Camila Wolpato Loureiro (2020), é possível entender que as obras de Paulo Freire são uma fonte do debate decolonial. Mas principalmente, que o autor fornece importante contribuição para a constituição e fortalecimento de um espaço pedagógico decolonial. Em toda a sua obra, Freire denuncia o colonialismo e anuncia, experimentando, a criação política e pedagógica de libertação da opressão.

Freire nos convida a "agir-pensar-agir", para a construção de um mundo mais justo e que respeite a busca ontológica de todos os homens e mulheres de "Ser Mais". Entretanto, "Ser Mais" não se refere à um ato individual de crescimento meritocrático, mas sim uma construção coletiva de sujeitos que buscam superar suas limitações, inclusive sócio-históricas. Na dialética freiriana, mais do que denunciar as situações e sistemas opressivos, é preciso anunciar possibilidades de superação desse contexto que oprime homens e mulheres na Abya Yala.

Tais opções ético-políticas nos impelem a destacar a relevância das pedagogias decoloniais ${ }^{8}$ que pensam a Abya Yala como local de enunciação e produção de saberes

\footnotetext{
8 É importante afirmarmos que as pedagogias decoloniais não sinônimas das pedagogias latino-americanas. Essas últimas dizem respeito à todas as formas de produção intelectual pedagógica construídas em Abya Yala, mas que não necessariamente questionem os paradigmas europeus e norte-americanocentrados. Para
} 
pedagógicos. Ainda que reconheçam a contribuição do "Norte", agem por um pensamento pedagógico desde paradigmas outros. Trabalhando para a superação do exotismo, da violência e da dor colonial, na valorização dos/as "oprimidos/as" (FREIRE, 1987) e "condenados da terra" (FANON, 2015).

De forma sucinta, as pedagogias decoloniais apontam para o fortalecimento da autonomia de grupos colocados à margem, como povos indígenas, negros/as e campesinos/as. Esses posicionamentos e compreensões pedagógicas se aliam com os da pedagogia crítica iniciada por Paulo Freire a partir dos anos 1960. Ambas se contrapõem a uma educação bancária e buscam a construção de conhecimentos a partir da problematização e transformação da realidade concreta de educandos/as e educadores/as. (LOUREIRO, 2020).

\section{DENÚNCIAS E ANÚNCIOS: AS PEDAGOGIAS DECOLONIAIS NO NOSSO TEMPO HISTÓRICO}

Com o arcabouço teórico mobilizado até aqui, estamos habilitados/as a observar os efeitos da atual pandemia de COVID-19 e do capitalismo mundial, no campo educacional. Retomemos nossa pergunta central: Em que medida é possível o desenvolvimento de um espaço favorável às pedagogias decoloniais, alicerçadas nos conhecimentos da/na Abya Yala?

Na exceção do confinamento do distanciamento físico, o que fica mais evidente é o crescimento do debate sobre educação à distância e ensino remoto. Para Carolina Catini (2020) o distanciamento físico acelerou um processo que já estava em curso, a introdução intensiva da tecnologia na relação educativa. Certamente - apesar das discrepâncias sociais de acesso aos meios digitais nos diferentes níveis de ensino -, tem crescido exponencialmente o uso de ferramentas digitais no espaço pedagógico. Seja para a produção e compartilhamento de materiais didáticos, como para a produção de aulas via plataformas como Youtube ou por ferramentas como Zoom, Google Meet, Jitsi, Teams, Skype, etc.

saber mais sobre a temática, sugiro a leitura dos livros: a) "Fontes da Pedagogia Latino-Americana: uma antologia”, organizado por STRECK, 2010; b) E também "Fontes da Pedagogia Latino-Americana: heranças (des)coloniais”, organizado por STRECK; MORETTI; ADAMS, 2019. 
O uso da tecnologia na educação não é algo novo. Como afirma Adams (et al, 2013) as tecnologias são criações humanas e, portanto, agem conforme determinado modo de compreender, ser e agir individuais e coletivos, sobre a realidade concreta. Cabe destacar que Freire criticou, em diversos momentos de sua obra (FREIRE, 1992; 2002) esse dualismo entre divinização e demonologização da tecnologia, que não deveria ser vista nem como salvadora, nem como promotora de todos os males (COSTA; et al, 2020). Afirmava o autor: "o avanço da ciência e da tecnologia não é tarefa de demônios, mas sim a expressão da criatividade humana" (FREIRE, 1984, p. 1).

Entretanto, olhemos de forma crítica para a introdução de tecnologias digitais nas aulas à distância. Além de ampliar em larga escala a produtividade do trabalho, também introduz uma nova divisão do trabalho intelectual dos profissionais de educação. Catini (2020) apresenta exemplo dessa parcialização a partir do uso de inteligência artificial para correção de provas no ensino superior privado, que só é possível através do esgotamento máximo das capacidades intelectuais de professores/as com mais de 3 mil alunos/as. Segundo a autora, em algumas escolas da rede básica de São Paulo, atualmente tem sido empregado um software no qual se insere o resultado das avaliações do/a aluno/a e o algoritmo calcula quais seriam as competências e habilidades que os/as educandos/as estão "deficitários".

Essa mecanização utilitária da educação decorre de uma crescente introjeção da racionalidade neoliberal no espaço pedagógico. A avaliação de resultados é a medida de produtividade das escolas lidas como empresas. Nesse cenário, o trabalho do/a educador/a é cada vez mais compartimentalizado em prol de uma pretensa avaliação positiva. Não se trata de uma crítica a tecnologia em si, mas sim de confrontar mais uma transformação do capital, buscando coletivamente formas de ampliar o controle do processo de trabalho intelectual dos professore/as. Nesse processo, a Educação Popular e as pedagogias críticas e decoloniais podem ser vistas como acumulados históricos, já que ampliam as referências a outros sujeitos individuais e coletivos que travam há séculos lutas contra a colonialidade (LOUREIRO, et al. 2020).

Mas não podemos negar que a realidade pedagógica de conexão remota ainda é pouco conhecida e por isso apresenta muitos desafios para os/as professores/aspesquisadores/as críticos. Considerando se tratar de um tema urgente, penso ser interessante estabelecermos pelo menos três desafios mais evidentes desse cenário. 
O primeiro desafio se dá na diretividade das aulas com o uso de ferramentas digitais. Penso que os avanços já feitos por propostas dialógicas deram um passo atrás com o distanciamento físico pois o/ a professor/a, nas aulas digitais, dá as regras e estabelece quem e quando os/as alunos/as devem e podem interagir na aula. Atos como ligar e desligar o microfone para poder falar, ouvir e ser ouvido se tornaram frequentes, fazendo com que o diálogo caia cada vez mais em um monólogo. Algumas plataformas, por exemplo, limitam à interação apenas via comentário escrito, o que torna o diálogo e troca ainda mais difíceis. ${ }^{9}$

Atualmente a maior pesquisa que mapeia a situação de trabalho dos/as professores/as no Brasil, foi promovida pelo Grupo de Estudos sobre Política Educacional e Trabalho Docente da Universidade Federal de Minas Gerais (GESTRADO/UFMG) em parceria com a Confederação Nacional dos Trabalhadores em Educação (CNTE). Intitulada "Trabalho Docente em Tempos de Pandemia", na pesquisa foram entrevistados/as 15.654 docentes de todos os estados da federação e DF ${ }^{10}$.

A pesquisa fornece um número riquíssimo de informações acerca das condições de trabalho dos profissionais da educação no atual momento de pandemia do COVID-19. Corroborando com nosso argumento, na pesquisa 46\% dos/as docentes disse que a participação diminuiu um pouco e cerca de 38\% afirma que a participação diminui drasticamente nas aulas remotas. Os dois principais motivos apontados para a decaída na participação são, para 53\% dos professores/as em função de os estudantes não se sentirem motivados para realizar as atividades propostas. E fica ainda mais evidente a falta de participação quando $80 \%$ dos/as docentes entende que os/as estudantes simplesmente não interagem pois, não possuem acesso à internet e aos demais recursos básicos necessários.

O que nos remete ao nosso segundo desafio acerca do ensino remoto e da busca por afirmação de um ensino domiciliar (homeschooling). Esse elemento evidencia as desigualdades sociais e a discrepância no acesso ao ensino domiciliar entre as classes

\footnotetext{
${ }^{9}$ Vale destacarmos que apenas o uso de mídias digitais em si mesmas, não necessariamente está dentro do campo de produção da educação à distância. E é nesse sentido que estamos entendendo o trabalho atual de professores/as-educandos/as que estão, antes se adaptando ao contexto não presencial, do que refletindo sobre as suas práticas e teorias.

$10 \mathrm{O}$ resumo técnico se encontra disponível em: <https://www.docencia.net.br/news >. Acesso em $28 / 07 / 2020$.
} 
opressoras e oprimidas. Em um mundo onde grande parcela da população enfrenta a ausência de infraestruturas mínimas como água encanada, saneamento básico, alimentação, espaço adequado de estudos, entre outros; apenas transpor as aulas presenciais por ambientes on-line não garante a aprendizagem.

O papel fundamental da escola fica ainda mais evidente quando percebemos que mais da metade da rede básica de ensino de São Paulo nunca acessou ou deu login no sistema de aulas online oferecido como ferramenta de continuidade pedagógica durante a pandemia (CATINI, 2020). Esse fenômeno demonstra que muitos/as dos/as educandos/as não possui infraestruturas mínimas de saneamento básico, acesso a aparelhos eletrônicos ou conexão com a internet.

O terceiro desafio está conectado ao segundo, pois dialoga sobre as mudanças do tempo de vida e do tempo de trabalho com o "trabalho em casa" (home office). Cesar Sanson (2010) argumenta que na sociedade pós-industrial o conhecimento, a comunicação e a cooperação passam a ser considerados como os principais recursos demandados aos sujeitos do trabalho, o que é considerado como trabalho imaterial.

Assim, o trabalho imaterial cria produtos imateriais, como conhecimento, informação, comunicação, relações ou reações emocionais. Se na teoria marxista o parâmetro utilizado para definir o valor de uma mercadoria é a quantidade de tempo de trabalho despendido para a sua produção; no trabalho em casa (imaterial) o tempo de trabalho e não-trabalho se confundem, não sendo possível medir quanto tempo o/a trabalhador/a, professor/a, pesquisador/a levou para produzir um conhecimento, por exemplo. Por isso, o trabalho em casa demanda cada vez mais engajamento total do/a trabalhador/a, mobilizando a lógica da concorrência e eficiência máxima.

Na pesquisa apresentada pelo GESTRAD0, 84,2\% dos/as entrevistados/as diz ter aumentado o tempo de preparação de suas aulas por conta do ensino remoto. E mais, a precariedade do trabalho docente fica evidente quando 89\% dos/as professores/as argumentam que não possuem nenhuma experiência anterior com o ensino remoto. Ao passo que a precarização se apresenta como projeto, quando 41,8\% afirmam não estar recebendo nenhuma formação para o uso de tecnologias digitais em suas práticas em aula. Para Catini (2020) a precariedade e a precarização da condição profissional do 
trabalho educativo são diretamente proporcionais ao poder totalitário de quem os coloca em pratica, seja o Estado, o empresariado ou os fundos de investimentos.

A irrupção de tais desafios trazem à tona uma forma de ser, saber e poder no qual o aspecto pedagógico não se compactua com a morosidade, mas exige transformações drásticas. Pode ser um momento de mudanças da própria forma como vemos e vivemos o mundo, como pontua Boaventura de Souza Santos (2020): “Torna-se possível ficar em casa e voltar a ter tempo para ler um livro e passar mais tempo com os filhos, consumir menos [...] A ideia conservadora de que não há alternativa ao modo de vida imposto pelo hipercapitalismo em que vivemos cai por terra" (SOUSA SANTOS, 2020, p.06).

Esse é um texto que não pretende se esgotar em si mesmo, assim, não trago certezas, mas busco abrir caminhos de discussões e questionamentos para que, juntos/as possamos compreendermos o nosso fazer e agir enquanto professores/as e pesquisadores/as engajados/as criticamente com os/as oprimidos/as. Entendo que no contexto atual as pedagogias críticas e decoloniais são cada vez mais urgentes, pois são propostas concretas de transformação das diversas realidades da Abya Yala. A fim de completar o par dialético denúncia/anúncio, julgo interessante elencar ao menos dois âmbitos em que podemos ver como as lutas sociais convergem com a produção de pedagogias outras/críticas/decoloniais.

Segundo Flávia Vieria e Javier Ghibaudi (2020) desde o início da pandemia e do isolamento físico, o Brasil tem vivenciado muitas ações para a diminuição dos impactos sociais desse contexto. Se por um lado, a clássica filantropia paternalista de doações milionárias de multinacionais como Itaú e Natura tem sido divulgada em horário nobre na televisão brasileira. Por outro existem frentes de solidariedade, alicerçadas principalmente nos movimentos sociais populares, como as campanhas "Vamos precisar de todo mundo" e "Periferia Viva", que: "São articulações de parceiros antigos que, no momento da pandemia, se juntaram novamente para defender a classe trabalhadora, isto é, se autodefender, dos descasos do sistema capitalista" (VIEIRA; GHIBAUDI, 2020, p. 292).

Através dessas experiências profundamente latino-americanas e brasileiras que podemos pensar o primeiro âmbito de superação das duas crises, o qual diz respeito à 
discussão de renda básica universal. Talvez esse debate não seja totalmente inovador, uma vez que já vem sendo feito há pelo menos três décadas na Abya Yala. Nessa proposta, os governos dão uma quantia mínima em dinheiro para todos os cidadãos/ãs, com base no status de trabalho e renda. A inovação se dá justamente por ser uma pauta que toma potência em um momento de distanciamento físico ocasionado por conta da pandemia de COVID-19 e da crise do capitalismo mundial.

No Brasil, o debate sobre um auxílio que ajudasse financeiramente as famílias mais empobrecidas do país só foi possível devido à intensa mobilização social, frente à redução da renda dos/as trabalhadores/as, ocasionado pelo fechamento das principais atividades produtivas e do crescimento exponencial das taxas de desempregados/as e desocupados/as nesse período. Após intensos debates e disputas entre governo e oposição, tanto no Congresso Nacional, quanto no Senado, foi instituída a Lei de no 13.982/2020, que prevê um auxílio emergencial de $\mathrm{R} \$ 600,00$ à $1.200,00$, durante três meses. Esse valor acabou sendo estendido em duas parcelas de igual valor e outras três parcelas de $\mathrm{R} \$ 300,00$.

Entretanto, é preciso ter cuidado, o auxílio emergencial é uma medida de contenção temporária. E mais, quando abordamos a questão de uma renda básica universal, precisamos estar atentos que esta pode ser lida de duas maneiras distintas: se por um lado não questiona o sistema capitalista neoliberal, mas funciona para sua manutenção; por outro lado, a distribuição de renda faz com que as desigualdades e concentração de riqueza seja minimamente abrandada, produzindo meios materiais possíveis para lutas sociais, políticas e pedagógicas que, daí sim, procurem quebrar o sistema moderno/colonialista. "Parece-nos, entretanto, que ela [a pandemia] também está evidenciando a longa tradição de valores solidários dos subalternos e, quem sabe, propiciando lutas e resistências inesperadas em futuro não tão distante" (VIEIRA; GHIBAUDI, 2020, p. 296)

0 segundo âmbito aborda diretamente o trabalho de profissionalização do educador/a na formação dos/as estudantes. Os pais ou responsáveis pelos educandos/as não possuem os instrumentos necessários para dar o mesmo suporte educacional, que profissionais capacitados/as nas diferentes áreas do conhecimento. Como afirma Silke Weber (2003) no reconhecimento da sua profissionalização o/a docente organiza, domina, sistematiza e constrói (junto aos/as alunos/as) os conhecimentos a serem 
trabalhados. Assim, transforma a massa de informações (hoje difundidas principalmente pelo uso da internet) em conhecimento com significados e reconhecimentos específicos para cada grupo de educandos/as.

O próprio Freire já afirmava em "Professora sim, tia não! Cartas à quem ousa ensinar", que o fazer docente exige seriedade, preparo científico, físico, emocional e afetivo: "A tarefa de ensinar é uma tarefa profissional que, no entanto, exige amorosidade, criatividade, competência científica mas recusa a estreiteza cientificista, que exige a capacidade de brigar pela liberdade sem a qual a própria tarefa fenece" (FREIRE, 1997, p. 09). Daí a necessidade de pensarmos os desafios e as potencialidades de um fazer educativo que procura superar o par modernidade/colonialidade, através da solidariedade na construção de um espaço pedagógico mais humano, igualitário e justo.

\section{CONSIDERAÇÕES FINAIS}

Ao longo de nosso debate, argumentei que a pandemia de COVID-19 não é a primeira (ou a será a última), o seu "diferencial" está na associação com o crescimento populacional e de transportes, a partir daí ela assume proporções poucas vezes experimentada na história da humanidade. Mais do que uma crise sanitária, no atual contexto presenciamos uma crise social e histórica provocada pelas correntes crises do capitalismo global. Os próprios sistemas capitalistas são as crises.

Parece lógico pensar que se os principais riscos decorrentes das duas crises - da pandemia do COVID-19 e do capitalismo -, são globais, logo, as políticas e os conhecimentos adquiridos devem ser coordenados, de forma mútua e compartilhada. E é nesse sentido que percebemos como as pedagogias críticas e decoloniais são imprescindíveis para as lutas sociais, políticas, ontológicas e epistêmicas de libertação.

Assim, as pedagogias decolonais são as práticas, estratégias e formas de fazer, construídas na afirmação da (re) existência e da (re) humanização (LOUREIRO, 2020). São as pedagogias que, segundo Walsh (2013), animam o pensar desde e com racionalidades e sistemas civilizatórios distintos. As pedagogias críticas e decoloniais valorizam 
possibilidades outras de ser, estar, fazer, pensar, escutar de modo outro, ancoradas em projetos horizontais e libertadores.

Por isso, nesse texto exercitamos a possibilidade de pensar o fazer profissional de educadores/as enquanto sujeitos historicamente situados. Ainda que os desafios tenham se alargado nesse momento, acredito que possamos entender que as pedagogias críticas e decoloniais não serão possíveis somente em um futuro longínquo (após as crises), mas elas já estão sendo através da solidariedade própria dos movimentos sociais populares da Abya Yala.

\section{REFERÊNCIAS}

ADAMS, Telmo, SCHUTZ, Vitor, STRAUB, Gilmar, MENEZES, Janaína (2013). Tecnologias digitais e educação: para qual desenvolvimento? Educação Unisinos. Vol.17, no 1 , pp.57-65.

BERNARDINO-COSTA, J.; MALDONADO-TORRES, N.; GROSFOGUEL, R. Introdução: Decolonialidade e pensamento afrodiaspórico. (2018). In: . (Orgs.).

Decolonialidade e pensamento afrodiaspórico. Belo Horizonte: Autêntica

CATINI, Carolina. 0 trabalho de educar numa sociedade sem futuro. Blog da Boitempo, São Paulo, 05/ 06/ 2020. Disponível em:

https://blogdaboitempo.com.br/2020/06/05/o-trabalho-de-educar-numa-sociedadesem-futuro. Acesso em: 15 Jun. 2020.

CANO, Wilson. América Latina: notas sobre a crise atual. Econ. soc. vol.18 no.3. pp. 603621, 2009. Disponível em: <

https://www.scielo.br/scielo.php?script=sci_arttext\&pid=S0104-

06182009000300008>. Acesso em: 25/ 09/ 2020.

COSTA, Alan, BEVILÁQUA, André, SANTOS, Helena, FIALHO, Vanessa. Paulo Freire Hoje: na Cibercultura. In: LOUREIRO, Camila, COSTA, Alan, PEREIRA, Thiago (Orgs.). Coleção Paulo Freire Hoje. Porto Alegre, Cirkula, 2020.

DAVIS, Angela. KLEIN, Naomi. Construindo movimentos: uma conversa em tempos de pandemia.Trad. Leonardo Marins. São Paulo: Boitempo, 2020.

DARDOT, Pierre; LAVAL, Cristhian. A prova política da pandemia. Blog da Boitempo, São Paulo, 26/ 03/ 2020. Disponível em: < https://blogdaboitempo.com.br/2020/03/26/dardot-e-laval-a-prova-politica-dapandemia/>. Acesso em: 04/ 05/ 2020. 
FANON, Frantz. Os Condenados da Terra. Juiz de Fora: UFJF, 2015.

FREIRE, Paulo. A máquina está a serviço de quem? Revista BITS, 1984, P.06.

FREIRE, Paulo. Pedagogia da Esperança. Um reencontro com a Pedagogia do Oprimido. Rio de Janeiro: Paz e Terra, 1992.

FREIRE, Paulo. Pedagogia do Oprimido. Rio de Janeiro: Paz e Terra, 1987.

FREIRE, Paulo. Professora sim, tia não! Cartas a quem ousa ensinar. Olho D’água, 1997.

HARARI, Yuval Noah. Na batalha contra o coronavírus, faltam líderes à humanidade. São Paulo: Companhia das Letras, 2020.

HARVEY, David. Política anticapitalista em tempos de coronavírus. Blog da Boitempo, São Paulo, 24/03/2020. Disponível em: < https://blogdaboitempo.com.br/2020/03/24/david-harvey-politica-anticapitalista-emtempos-de-coronavirus/>. Acesso em: 20/ 04/ 2020.

KRENAK, Ailton. 0 amanhã não está à venda. São Paulo: Companhia das Letras, 2020

LOUREIRO, Camila Wolpato. Paulo Freire, autor de práxis decolonial? [Dissertação de Mestrado]. Erechim: UFFS, 2020.

LOUREIRO, Camila Wolpato; MORETTI, Cheron Zanini; MOTA NETO, João Colares; FLEURI, Reinaldo Matias. Paulo Freire Hoje em Abya Yala. Cirkula: Porto Alegre, 2020.

LÖWY, Michel. Prefácio. In: TIBLE, Jean. Marx Selvagem. São Paulo: Annablume, 2013.

MARTÍ, José. Educação em Nossa América. Apresentação e organização Danilo R. Streck. Ijuí: Editora Unijuí, 2007.

MASCARO, Alysson. Crise e pandemia. São Paulo: Boitempo, 2020.

MOTA NETO, João Colares. Educação Popular e pensamento decolonial latinoamericano em Paulo Freire e Orlando Fals Borda. 2015, 370 f. Tese (Doutorado em Educação) - Universidade Federal do Pará, Belém, 2015.

SANSON, Cesar. Trabalho e Subjetividade: da sociedade industrial à sociedade pósindustrial. Cadernos IHU, v.8, n. 32. pp. 1-63, 2010.

SANTOS, Boaventura de Souza. A cruel pedagogia do vírus. Almeida: Coimbra, 2020.

STRECK, Danilo (Org.). Fontes da Pedagogia Latino-Americana: uma antologia. Belo Horizonte: Autêntica Editora, 2010.

STRECK, Danilo. MORETTI, Cheron. Colonialidade e insurgência: contribuições para uma pedagogia latino-americana. Revista Lusófona de Educação, № 24, 2013, p. 35-52.

STRECK, Danilo; MORETTI, Cheron; PITANO, Sandro. Paulo Freire na América Latina: tarefas daqueles/ as que se deslocam por que devem. In: GADOTTI, Moacir; CARNOY, 
Martin. Reinventando Freire: a práxis do Instituto Paulo Freire. São Paulo: Instituto Paulo Freire. Lemann center / Stanford Graduate School of Education, 2018, p. 37-46.

STRECK, Danilo; MORETTI, Cheron; ADAMS, Telmo (Org.). Fontes da Pedagogia LatinoAmericana: heranças (des)coloniais. Curitiba: Appris, 2019.

TIBLE, Jean. Marx Selvagem. São Paulo: Annablume, 2013.

TORRES, Carlos. A voz do intelectual latino-americano: uma biografia intelectual. In: GADOTTI, Moacir (Org.). Paulo Freire: uma biobliografia. Cortez: São Paulo, 1996. p. 117- 148.

TUBINO, Fidel J. La interculturalidad crítica como proyecto éticopolítico. Encuentro continental de educadores agustinos, Lima, p. 24-28 de Enero, 2005.

VIEIRA, Flávia; GHIBAUDI, Javier. Solidariedade como instrumento da luta política: reflexões a partir das resistências populares na Argentina e no Brasil em tempos de pandemia. In. ALMICO, Rita; GOODWIN JR., James; SARAIVA, Luiz (Orgs.). Na saúde e na doença: história, crises e epidemias. Reflexões da história econômica na época da covid19. São Paulo: Hucitec, 2020.

WALSH, Catherine. (Org.). Pedagogias decoloniales: prácticas insurgentes de resistir, (re) existir y (re) vivir. Tomo I. Serie Pensamiento Decolonial. Quito: Abya Yala, 2013.

WALSH, Catherine. Pedagogías decoloniales caminando y preguntando. Notas a Paulo Freire desde Abya Yala. Revista Entramados Educación y Sociedad, Mar del Plata, v. 1, n. 1, p. 17-31, 2014.

WEBER, Silke. Profissionalização docente e políticas públicas no Brasil. Educ. Soc., Campinas, vol. 24, n. 85, p. 1125-1154, dezembro 2003.

ZIZEK, Slavoj. Pandemia: Covid-19 e a reinvenção do comunismo. São Paulo: Boitempo, 2020. 